\title{
Academic performance and use of psychoactive drugs among healthcare students at a university in southern Brazil: cross-sectional study
}

Karine de Lima Sírio Boclin', Fernanda Fabian Callejon Cecílio", Gabriela Faélı', Gabriela Fanti"v Guilherme Centenaro" Thoany Pellizzari"', Emanuela Gaviolliv", Débora Nunes Mario "VII, Lilian Rigo'

School of Medicine, Faculdade Meridional (IMED), Passo Fundo (RS), Brazil

PhD. Professor, School of Medicine, Universidade Estácio de Sá (UESA), Rio de Janeiro (RJ), Brazil. (D) orcid.org/0000-0003-3130-8211

"Undergraduate Student, School of Medicine, Faculdade Meridional (IMED), Passo Fundo (RS), Brazil.

(D) orcid.org/0000-0002-3836-8834

'"Undergraduate Student, School of Medicine, Faculdade Meridional (IMED), Passo Fundo (RS), Brazil.

(D) orcid.org/0000-0003-2310-0509

"Undergraduate Student, School of Medicine, Faculdade Meridional (IMED), Passo Fundo (RS), Brazil.

(D) orcid.org/0000-0002-7578-4466

VUndergraduate Student, School of Medicine, Faculdade Meridional (IMED), Passo Fundo (RS), Brazil.

(D) orcid.org/0000-0003-4830-3361

"Undergraduate Student, School of Medicine, Faculdade Meridional (IMED), Passo Fundo (RS), Brazil.

(D) orcid.org/0000-0003-0225-0356

VIIMSc. Dental Surgeon, at a private clinic, Passo Fundo (RS), Brazil.

(D) orcid.org/0000-0003-2039-1670

VIIPhD. Professor, School of Medicine, Universidade Federal do Pampa (UNIPAMPA),

Uruguaiana (RS), Brazil.

(D) orcid.org/0000-0001-7021-3245

xphD. Professor, School of Dentistry, Postgraduate Program on Dentistry, Faculdade Meridional (IMED), Passo Fundo (RS), Brazil.

(D) orcid.org/0000-0003-3725-3047

KEY WORDS (MeSH terms):

Students, medical.

Students, dental.

Drug effects [Subheading]

Psychoactive drugs.

Academic performance.

AUTHORS' KEY WORDS:

Illicit drugs.

Licit drugs.

Higher education institution

\begin{abstract}
BACKGROUND: People have been using psychoactive substances for a long time. Over the last few years, this practice has spread among university students, who use these substances to improve their academic performance, relieve stress and increase concentration and memory.

OBJECTIVES: To estimate the use of psychoactive drugs among healthcare students at a higher education institution in the city of Passo Fundo (RS), Brazil, and to ascertain the associated demographic and lifestyle factors. DESIGN AND SETTING: Cross-sectional study in a higher education institution.

METHODS: We included 287 undergraduate medicine and dentistry students in this study. They answered a self-administered questionnaire regarding sociodemographic, lifestyle and health variables. The statistical analysis used univariate and bivariate analyses with Pearson's chi-square test (P-value $<0.05$ ). Multivariate analyses were used to estimate odds ratios (OR) and their respective $95 \%$ confidence intervals. The SPSS software, version 20.0, was used.

RESULTS: The prevalence of use of psychoactive substances among the students was $24.7 \%$. Among these students, high frequencies of psychoactive drugs had been prescribed by physicians (95.8\%) and for the purpose of relaxation or stress relief (73.2\%). Women, medical students (compared with dental students) and participants with lower academic performance were more likely to use psychoactive drugs. After the multivariate adjustment, the "course" and "academic performance" remained associated with use of psychoactive drugs. CONCLUSION: There was high prevalence of psychoactive drug use among the students at the higher education institution investigated. Some variables (female sex, medical students and low academic performance) were associated with the outcome.
\end{abstract}

\section{INTRODUCTION}

Throughout history, humans have resorted to the use of psychoactive substances for various purposes. Psychoactive drugs work on the brain, modifying its operation and changing mood, behavior and consciousness, which may lead to a state of dependence. Among these substances are licit drugs (alcohol and tobacco), illicit drugs (marijuana, cocaine, crack and others) and psychoactive drugs (tranquilizers, sedatives and strong analgesics). ${ }^{1}$

Generations of students have used brain stimulants, food supplements, drugs subject to medical prescription, amphetamines and energy drinks in order to enhance their mental faculties, namely memory, concentration, reasoning and language, which are inherent to studying and academic development. ${ }^{2-4}$

The main substances used for this purpose are caffeine, methylphenidate (MPH), modafinil, piracetam, energy drinks and amphetamines. Although the specific action mechanisms may vary, psychostimulants usually work directly or indirectly through dopamine ${ }^{5,6}$, motivation, attention and excitement. ${ }^{7}$

MPH (also known as Ritalin ${ }^{\mathrm{mw}}$ ) and dextroamphetamine (d-AMP) are the most commonly used non-medical substances, although other amphetamine formulations have also been used. However, these substances, which belong to the class of amphetamines, present significant risk of dependence. ${ }^{8}$ Among students using methylphenidate, most of them have used it in highly stressful periods of academic studies. ${ }^{9}$ Thus, studies have estimated that $5 \%$ to $35 \%$ of university students use these drugs to improve their academic performance, stimulate cognitive function and decrease physical and mental fatigue., ${ }^{2,10}$ 
Hence, the increasing use of psychoactive drugs for non-therapeutic purposes creates the need to inform students and raise their awareness about the real risks of over-the-counter psychoactive drugs and their harmful effects on health, such as increased blood pressure, arrhythmias, headaches, overdose and depression..$^{2,10,11}$ Therefore, studies providing data on the use of psychoactive substances among healthcare students become relevant. Understanding and reflecting on the issues raised by this topic may allow the creation of effective intervention strategies.

\section{OBJECTIVE}

The aim of the present study was to estimate the use of psychoactive drugs among healthcare students at a higher education institution located in the city of Passo Fundo (RS), Brazil, and to ascertain the associated demographic and lifestyle factors.

\section{METHODS}

\section{Ethical considerations}

This study was approved by the institution's ethics committee, under investigation no. 2.014.448 and CAAE 66373317.6.0000.5319 (April 12, 2017). The voluntary nature of the participation and the confidential nature of the information were explained to the students. All participants signed a free and informed consent form and there was no conflict of interest among the authors.

\section{Study population}

The analyses presented here form part of a larger cross-sectional study on the sociodemographic, lifestyle and health profiles of healthcare students at a higher education institution located in the city of Passo Fundo (RS), Brazil. Every stage of the study was conducted by the students of the scientific methodology course that was offered by the medical school of this institution in the first semester of 2017.

The target population included medicine and dentistry students of a higher education institution. Out of 327 students enrolled in the first semester of 2017 (169 medical students and 158 dental students), 287 participated in this study (148 medical students and 139 dental students), thus resulting in assessment of $87.8 \%$ of the total population.

\section{Data collection}

The data were collected through a self-administered questionnaire containing closed questions, which was applied during a class to those of the students present who had agreed to participate in the study. This questionnaire was produced based on questions retrieved from a previous study on a similar population: "Drug Use - adaptation of a questionnaire proposed by the World Health Organization (WHO)". ${ }^{12}$

\section{Outcome variable}

"Use of psychoactive drugs" was considered to be the outcome. This was evaluated through the question "Do you use psychoactive drugs? (yes or no)".

Regarding descriptive variables, psychoactive drug users were questioned about medical prescriptions (yes, no); purpose of use (relaxation or stress relief, sleep stimulation, sleep suppression, pain control, increased cognitive ability, increased attention for studying, anxiety or depression); duration of drug use (less than six months, six months to one year, one to two years or three years or more); frequency of drug use (daily, at least once a week, at least once a month or rarely); need to increase the dose (yes or no); and side effects (reduced appetite, euphoria, anxiety, tachycardia, irritability, tremors or headache).

\section{Covariables}

The variables considered were sex (female or male), age (17 to 20 years old or over 20 years old); marital status (married/cohabitating or separated/widowed/single); course (medicine or dentistry); semester (first to eighth); religious practice (yes or no); living situation (alone or with relatives and/or friends); and expected academic performance (better than or equal to expected or below expected).

\section{Data analysis}

In the univariate and bivariate analyses, summary measurements (absolute and relative frequencies) were calculated. To analyze the statistical differences between the categorical variables, Pearson's chi-square test was used, in which the results with P-values lower than $5 \%$ (P-value $<0.05)$ were considered statistically significant. In the multivariate analysis, crude and adjusted odds ratios (OR) and their respective $95 \%$ confidence intervals (CI) were estimated according to the exposure variables. Variables with $\mathrm{P}$-value $<0.20$ in the bivariate analyses were included in the multivariate models. The data were analyzed using the Statistical Package for the Social Sciences (SPSS) software, version 20.0.

\section{RESULTS}

The study population consisted predominantly of female university students aged 20 to 36 years. The population was divided into virtually equal proportions for the dental and medical schools. Table 1 presents the characteristics of the students who were and were not using psychoactive drugs.

Among the students who were using psychoactive drugs, high frequencies of psychoactive drugs had been prescribed by physicians (95.8\%) and with the purpose of relaxation or stress relief (73.2\%). Most of these students had been using the drugs for one or two years $(35.2 \%)$ and were taking them daily (71.9\%). It was noted that almost half of the students had needed to increase the dose from the initial drug prescription (49.3\%). Many students reported having some side effect (59.2\%), such as headaches (23.8\%) (Table 1). 
Table 2 presents the prevalence of psychoactive drug use stratified according to the covariables. Higher prevalence were observed among women, medical students and participants with lower-thanexpected academic performance $(\mathrm{P}$-value $<0.05)$. As anticipated, the same variables were associated with the use of psychoactive drugs in the crude models. Thus, women, medical students (compared with dental students) and participants with lower academic performance were more likely to use psychoactive drugs. After the multivariate adjustments, the variables of "sex", "course" and "school performance" remained significant.

\section{DISCUSSION}

The aim of the present study was to estimate the use of psychoactive drugs among healthcare students at a higher education institution located in the city of Passo Fundo (RS), Brazil, and to ascertain the associated demographic and lifestyle factors. It was observed that most of the university students interviewed who were using psychoactive drugs were obtaining them through medical prescription (95.8\%). Among these, the majority reported using this type of medication for relaxation or stress relief (73.2\%).

For young people today, university is the time for preparation to face the professional world. This is an important step in an increasingly competitive and challenging society. During the academic course, students feel that they are under pressure to succeed and feel the need to continually surpass themselves. Hence, improvement of concentration, memory and attention is the need that leads university students to misuse psychoactive drugs. ${ }^{8}$

Previous studies targeting student populations have indicated that the prevalence rates for the use of stimulants are between $1 \%$ and $38 \%{ }^{8}$ The reasons for their use that university students have stated include optimization of studies, increased concentration, compensation for sleep deprivation and enhancement of moments of relaxation. ${ }^{8,13}$

According to Wilens et al., ${ }^{10}$ higher education requires a certain level of development of cognitive function and, in medical schools, this level is particularly high. Thus, students use brain stimulants to increase academic performance.

This study showed an association between the use of psychoactive drugs and women. This result agrees with the findings from other studies such as the one by Lemos et al., ${ }^{14}$ which showed that there was higher alcohol consumption among men and higher use of tranquilizers among women. Boskovitz et al. ${ }^{15}$ concluded that while men were more likely to consume alcohol, solvents, marijuana and cocaine, women were more likely to use tranquillizers.

According to Simoni-Wastila et al. ${ }^{16}$ there is a pattern of medicalization among adult women, because they seek relief for their domestic or professional problems through "chemical tranquilizers".

The present study also found that psychoactive drug use had an influence on school performance. In a previous study, it was observed that a slight increase in concentration and motivation
Table 1. Characteristics of the population of healthcare students at a higher education institution who were using psychoactive drugs $(n=71)$ and were not using psychoactive drugs $(n=216)$, in the city of Passo Fundo (RS), Brazil, 2017

\begin{tabular}{|c|c|c|c|c|}
\hline & \multicolumn{2}{|c|}{ Using } & \multicolumn{2}{|c|}{ Not using } \\
\hline & $\mathbf{n}$ & $\%$ & $\mathbf{n}$ & $\%$ \\
\hline \multicolumn{5}{|l|}{ Sex } \\
\hline Male & 13 & 18.3 & 63 & 29.2 \\
\hline Female & 58 & 81.7 & 153 & 70.8 \\
\hline \multicolumn{5}{|l|}{ Age category (years) } \\
\hline 17 to 20 & 25 & 35.2 & 91 & 42.1 \\
\hline 21 to 36 & 46 & 64.8 & 125 & 57.9 \\
\hline \multicolumn{5}{|l|}{ Course } \\
\hline Medicine & 49 & 69.0 & 99 & 45.8 \\
\hline Dentistry & 22 & 31.0 & 117 & 54.2 \\
\hline \multicolumn{5}{|l|}{ Semester } \\
\hline I to III & 38 & 53.5 & 95 & 44.0 \\
\hline IV to VIII & 33 & 46.5 & 121 & 56.0 \\
\hline \multicolumn{5}{|l|}{ Religion } \\
\hline Non-practicing & 14 & 19.7 & 29 & 13.4 \\
\hline Some religious practice & 57 & 80.3 & 187 & 86.6 \\
\hline \multicolumn{5}{|l|}{ Living situation } \\
\hline Alone & 35 & 4.93 & 101 & 46.8 \\
\hline With relatives/friends & 36 & 50.7 & 115 & 53.2 \\
\hline \multicolumn{5}{|l|}{ Marital status } \\
\hline Married/cohabitating & - & - & 13 & 6.0 \\
\hline Separated/widowed/single & 48 & 100 & 203 & 94.0 \\
\hline \multicolumn{5}{|l|}{ Expected academic performance } \\
\hline Higher than or equal to expected & 30 & 16.7 & 7 & 13.5 \\
\hline Below expected & 40 & 42.3 & 133 & 61.6 \\
\hline Drugs prescribed by physicians & 41 & 57.7 & 57.7 & 38.4 \\
\hline Yes & 68 & 95.7 & - & - \\
\hline No & 3 & 4.3 & - & - \\
\hline Purpose of use & & & - & - \\
\hline Relaxation or stress relief & 52 & 73.2 & & \\
\hline Sleep stimulation & 8 & 11.3 & - & - \\
\hline Sleep suppression & 1 & 1.4 & - & - \\
\hline Pain control & 5 & 7.0 & - & - \\
\hline Increased cognitive ability & 3 & 4.3 & - & - \\
\hline Increased attention for studying & 2 & 2.8 & - & - \\
\hline Anxiety & - & - & - & - \\
\hline Depression & - & - & - & - \\
\hline \multicolumn{5}{|l|}{ Duration of drug use } \\
\hline Less than 6 months & 18 & 25.4 & - & - \\
\hline 6 months to 1 year & 6 & 8.3 & - & - \\
\hline 1 to 3 years & 25 & 35.3 & - & - \\
\hline 3 years or more & 22 & 31 & - & - \\
\hline \multicolumn{5}{|l|}{ Frequency of drug use } \\
\hline Daily & 51 & 71.9 & - & - \\
\hline At least once a week & 10 & 14 & - & - \\
\hline At least once a month & 7 & 9.8 & - & - \\
\hline Rarely & 3 & 4.3 & - & - \\
\hline \multicolumn{5}{|l|}{ Need to increase the dose } \\
\hline Yes & 35 & 49.3 & - & - \\
\hline No & 36 & 50.7 & - & - \\
\hline \multicolumn{5}{|l|}{ Side effects } \\
\hline Yes & 42 & 59.2 & - & - \\
\hline No & 29 & 40.8 & - & - \\
\hline
\end{tabular}


was achieved through use of psychoactive drugs. ${ }^{17}$ A study by Hildt et al. ${ }^{8}$ emphasized that there was a scarcity of real observed cognitive effects, given that the students reported that there was an increase in concentration and memory capacity after using such drugs. However, despite this positive subjective experience, few students reported that drug use had any real objective effect on academic outcomes. This raises the hypothesis that there might be a motivational effect associated with psychoactive drugs that is more important than the real effect on individual capacities. ${ }^{8}$ In some studies, many students on medications reported having high stress levels, especially before final exams or the due dates for handing in papers., ${ }^{9,18,19}$

In the present study, medical students showed higher prevalence of psychoactive drug use than dental students. In a study conducted by Webb et al. ${ }^{13}$ among medical students in the United States, it was suggested that $15 \%$ of the students were using stimulants during the academic course. It was found that $83 \%$ of the students were using stimulants specifically to improve academic performance.

Several authors have pointed out that the peculiar characteristics of medical schools may be contributing to the increased use of psychoactive substances among students. These characteristics include high course load, responsibility for patient healing, ethical issues, deaths of patients under student care and facilitated access to certain drugs that are restricted to healthcare professionals. ${ }^{20}$

In the present study, most of the students reported using this type of medication for the purpose of relaxation or stress relief (73.2\%). Medical school has been described as a source of stress for students, who report especially the loss of personal freedom, excessive academic pressures and feelings of dehumanization. ${ }^{21}$ They also complain about the lack of leisure time and the strong competition among colleagues. These and other factors such as contact with sick patients predispose towards appearance of depressive conditions, anxious reactions, obsessive-compulsive neurosis and hypochondria, which lead students to use psychoactive drugs. ${ }^{22}$

Some studies have already proven the high prevalence of stress, anxiety and depression among medical students. ${ }^{23}$ According to the study by Mesquita et al., ${ }^{24}$ the students themselves believe that the stress of medical school is a major factor for their use of drugs, particularly the stress relating to competitiveness, the intense course load, the abrupt transition from theoretical activities to practice and the medical residency test.

Medical students in the United States have been found to be more susceptible to developing symptoms of stress and dissatisfaction, and greater severity of signs of psychiatric illnesses. ${ }^{25,26}$ Medical students have been selected as the target population in a number of studies, which shows that there is higher concern regarding this specific group, given these individuals' greater knowledge of pharmacology and greater access to these substances. ${ }^{27-29}$

In another study, in which medical students stood out because of their facilitated access to these substances, the euphoric effect associated with recreational use was emphasized as an explanation for non-medical consumption of psychoactive substances. ${ }^{30}$

Consumption of psychoactive drugs has produced social and health problems worldwide, especially because of the increasing

Table 2. Prevalence (\%) and crude and adjusted odds ratio (OR) with respective $95 \%$ confidence intervals ( $95 \% \mathrm{Cl}$ ) for psychoactive drug use among healthcare students at a higher education institution in the city of Passo Fundo (RS), Brazil, 2017

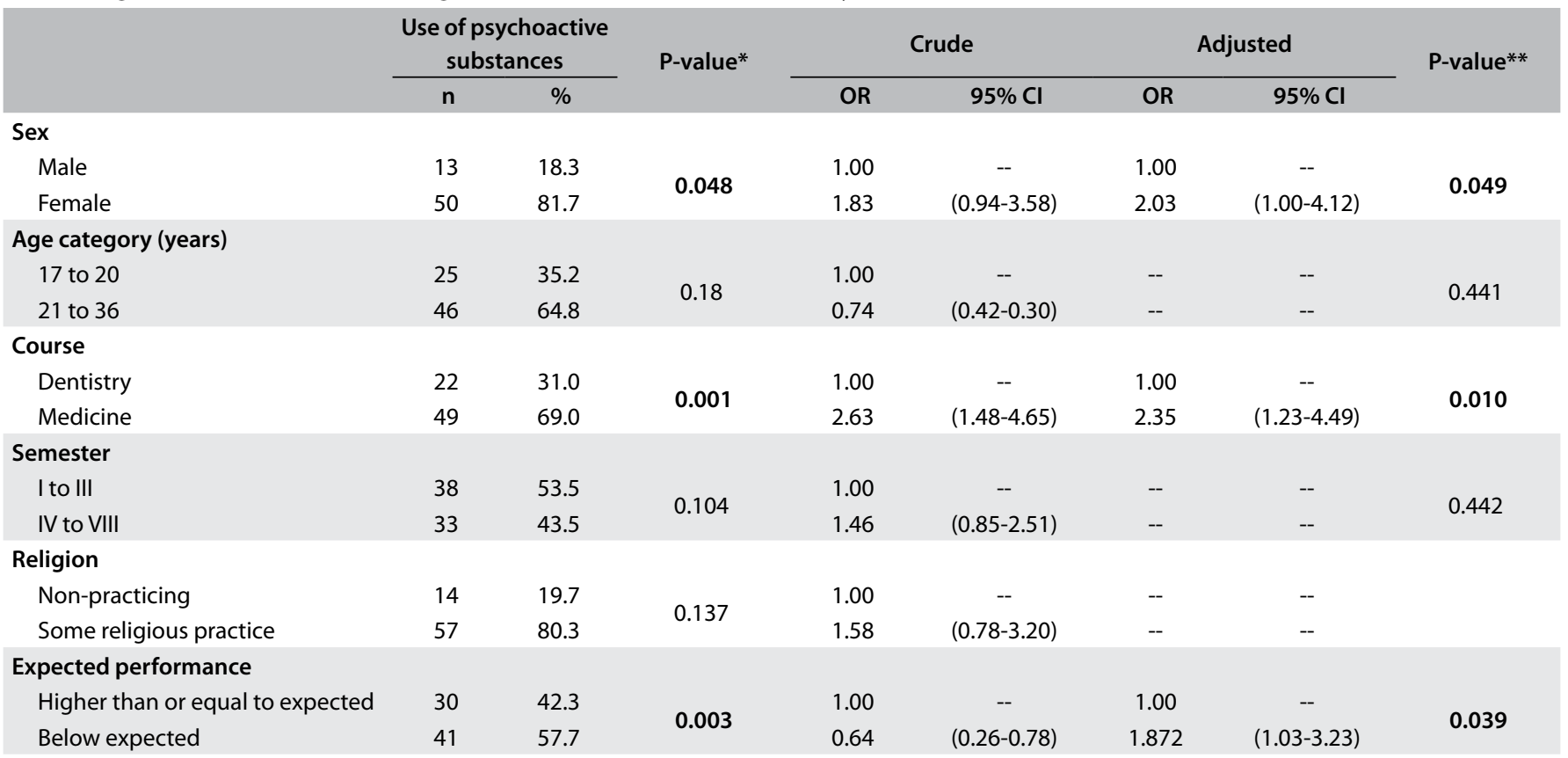


prevalence of these drugs. ${ }^{14}$ Therefore, there is a need to implement interventions and increase student awareness about the potential effects produced by these substances. It is also crucial for this issue to be addressed in healthcare courses, because students can be considered to be an at-risk group regarding the use of psychostimulants and, in the future, they may be faced with this situation as professionals. ${ }^{31}$

According to Dal Pizzol et al., ${ }^{32}$ the guidelines for public actions to prevent drug misuse should include educational campaigns targeted to the youth population with an emphasis on the most common psychoactive drugs. In addition, control over sales to minors and sales that are contrary to other restrictions established through health surveillance legislation should be reinforced.

One of the main areas of intervention will lie within improving the information and awareness of this student population regarding psychoactive drugs and their clinical and ethical effects, so as to prevent use and decrease the number of users.

Few scientific data on the effects of psychoactive substances or even on their long-term use have been published in the literature. Many of these studies have only indicated the growing trend in use among young people, without estimating further side effects, addictions or pathological conditions. Precisely because of the lack of data, the aim in this study was to ascertain the degree of use of psychoactive drugs among young students, in order to correlate this with deficiencies in their academic performance. Additionally, the aim was to observe whether the students were under medical care or were self-medicating, which is another matter of controversy within the academic environment. From analysis on the results, a high prevalence of psychoactive drug use was found, thus corroborating the scientific evidence.

The present study may have provided an important tool for further scientific studies focusing on the academic population of university courses with high course loads. From reflection on the increasing use of psychoactive drugs, it can be noted that this topic requires greater attention from the scientific community, to augment the sparse literature that currently exists and to obtain further data and reach more conclusions on this topic.

Therefore, it is necessary to implement interventions and increase the population's awareness of the potential effects produced by psychoactive substances. Considering that the participants in the present study were healthcare students, it was expected that the consumption of stimulants would be lower, because such students are aware of the risks of these substances. However, what was most striking to us was the fact that most of these users had a medical prescription for the use of such drugs.

\section{CONCLUSION}

From the results obtained, it was possible to conclude that:

- The use of psychoactive drugs among healthcare students at the higher education institution investigated was high, even though this use was via medical prescription.
- There was an association between the use of psychoactive drugs and some factors, with higher prevalence among women, medical students and subjects with lower-than-expected academic performance.

\section{REFERENCES}

1. Nery Filho A, Torres IMAP. Drogas: isso Ihe interessa?: confira aqui [Drugs: does it matter?: check here]. Salvador; Universidade Federal da Bahia; 2002.

2. Arria AM, Caldeira KM, Kasperski SJ, et al. Increased alcohol consumption, nonmedical prescription drug use, and illicit drug use are associated with energy drink consumption among college students. J Addict Med. 2010;4(2):74-80. PMID: 20729975; doi: 10.1097/ADM.0b013e3181aa8dd4.

3. Canterbury RJ, Lloyd E. Smart drugs: Implications of student use. J Prim Prev. 1994;14(3):197-207. PMID: 24258820; doi: 10.1007/BF01324593.

4. Rose SP."Smart drugs": do they work? Are they ethical? Will they be legal? Nat Rev Neurosci. 2002;3(12):975-9. PMID: 12461554; doi: 10.1038/nrn984

5. Fleckenstein AE, VolzTJ, Riddle EL, Gibb JW, Hanson GR. New insights into the mechanism of action of amphetamines. Annu Rev Pharmacol Toxicol. 2007;47:681-98. PMID: 17209801; doi: 10.1146/annurev. pharmtox.47.120505.105140.

6. Volkow ND, Fowler JS, Logan J, et al. Effects of modafinil on dopamine and dopamine transporters in the male human brain: clinical implications. JAMA. 2009;301 (11):1148-54. PMID: 19293415; doi: 10.1001/jama.2009.351.

7. Kapur S, Mizrahi R, Li M. From dopamine to salience to psychosis--linking biology, pharmacology and phenomenology of psychosis. Schizophr Res. 2005;79(1):59-68. PMID: 16005191; doi: 10.1016/j.schres.2005.01.003.

8. Hildt E, Lieb K, Bagusat C, Franke AG. Reflections on Addiction in Students Using Stimulants for Neuroenhancement: A Preliminary Interview Study. Biomed Res Int. 2015;2015:621075. PMID: 26064931; doi: 10.1155/2015/621075.

9. DeSantis AD, Webb EM, Noar SM. Illicit use of prescription ADHD medications on a college campus: a multimethodological approach. J Am Coll Health. 2008;57(3):315-24. PMID: 18980888; doi: 10.3200/JACH.57.3.315-324

10. Wilens TE, Adler LA, Adams J, et al. Misuse and diversion of stimulants prescribed for ADHD: a systematic review of the literature. J Am Acad Child Adolesc Psychiatry. 2008;47(1):21-31. PMID: 18174822; doi: 10.1097/chi.0b013e31815a56f1.

11. Weyandt $L L$, Janusis $G$, Wilson $K G$, et al. Nonmedical prescription stimulant use among a sample of college students: relationship with psychological variables. J Atten Disord. 2009;13(3):284-96. PMID: 19767596; doi: 10.1177/1087054709342212.

12. Smart RG, Hughes PH, Johnston LD, et al. A methodology for students drug-use surveys (WHO offset publication; no. 50). Geneva: World Health Organization; 1980. ISBN-10: 9241700505.

13. Webb JR, Valasek MA, North CS. Prevalence of stimulant use in a sample of US medical students. Ann Clin Psychiatry. 2013;25(1):27-32. PMID: 23376867.

14. Lemos KM, Neves NMBC, Kuwano AY, et al. Uso de substâncias psicoativas entre estudantes de Medicina de Salvador (BA) [Psychoactive substance use by medical students from Salvador (BA)]. Arch Clin Psychiatry (São Paulo). 2007;34(3):118-24. doi: 10.1590/S0101-60832007000300003. 
15. Boskovitz EP, Cruz E, Chiaravalloti Neto F, et al. Uso de drogas entre estudantes universitários em São José do Rio Preto, São Paulo [Use of drugs among university students in Sao Jose do Rio Preto, Sao Paulo]. Rev Psiquiatr Clín (São Paulo). 1995;22(3):87-93.

16. Simoni-Wastila L, Ritter G, Strickler G. Gender and other factors associated with the nonmedical use of abusable prescription drugs. Subst Use Misuse. 2004;39(1):1-23. PMID: 15002942.

17. Ragan Cl, Bard I, Singh I; Independent Scientific Committee on Drugs. What should we do about student use of cognitive enhancers? An analysis of current evidence. Neuropharmacology. 2013;64:588-95. PMID: 22732441; doi: 10.1016/j.neuropharm.2012.06.016.

18. Mache S, Eickenhorst P, Vitzthum K, Klapp BF, Groneberg DA. Cognitiveenhancing substance use at German universities: frequency, reasons and gender differences. Wien Med Wochenschr. 2012;162(11-12):262-71. PMID: 22707077; doi: 10.1007/s10354-012-0115-y.

19. Schelle KJ, Olthof BM, Reintjes W, et al. A survey of substance use for cognitive enhancement by university students in the Netherlands. Front Syst Neurosci. 2015;9:10. PMID: 25741248; doi: 10.3389/fnsys.2015.00010.

20. Millan LR, Arruda PC. Assistência psicológica ao estudante de medicina: 21 anos de experiência [Psychological assistance to medical students: 21 years of experience]. Rev Assoc Med Bras 2008;54(1):90-4. PMID: 18392493; doi: 10.1590/S0104-42302008000100027.

21. Lima RL, Soares MEC, Prado SN, Albuquerque GSC. Estresse do estudante de medicina e rendimento acadêmico [Stress among medical students and academic performance]. Rev Bras Educ Méd. 2016:40(4):678-84. doi: 10.1590/1981-52712015v40n4e01532015.

22. Lloyd C, Gartrell NK. Psychiatric symptoms in medical students. Compr Psychiatry. 1984;25(6):552-65. PMID: 6509959; doi: 10.1016/0010440x(84)90036-1.

23. Costa EF, Santana YS, Santos AT, et al. Sintomas depressivos entre internos de medicina em uma universidade pública brasileira [Depressive symptoms among medical intern students in a Brazilian public university]. Rev Assoc Med Bras (1992). 2012;58(1):53-9. PMID: 22392317; doi: 10.1590/S0104-42302012000100015

24. Mesquita AM, Laranjeira R, Dunn J. Psychoactive drug use by medical students: a review of the national and international literature. Sao Paulo Med J. 1997;1 15(1)::1356-65. PMID: 9293117; doi: 10.1590/S151631801997000100007

25. Davidson VM. Coping styles of women medical students. J Med Educ. 1978;53(11):902-7.PMID: 712786; doi: 10.1097/00001888-197811000-00003.

26. Stewart SM, Betson C, Marshall I, et al. Stress and vulnerability in medical students. Med Educ. 1995;29(2):119-27. PMID: 7623698; doi: 10.1111/j.1365-2923.1995.tb02814.x.

27. Emanuel RM, Frellsen SL, Kashima KJ, et al. Cognitive enhancement drug use among future physicians: findings from a multi-institutional census of medical students. J Gen Intern Med. 2013;28(8):1028-34. PMID: 23595918; doi: 10.1007/s11606-012-2249-4.
28. Habibzadeh A, Alizadeh M, Malek A, et al. Illicit methylphenidate use among Iranian medical students: prevalence and knowledge. Drug Des Devel Ther. 2011;5:71-6. PMID: 21340040; doi: 10.2147/ DDDT.S13818.

29. Micoulaud-Franchi J-A, MacGregor A, Fond G. A preliminary study on cognitive enhancer consumption behaviors and motives of French Medicine and Pharmacology students. Eur Rev Med Pharmacol Sci.2014;18(13):1875-8. PMID: 25010616

30. Partridge B, Bell S, Lucke J, Hall W. Australian university students' attitudes towards the use of prescription stimulants as cognitive enhancers: perceived patterns of use, efficacy and safety. Drug Alcohol Rev. 2013;32(3):295-302. PMID: 23121045; doi: 10.1111/ dar.12005.

31. Finger G, Silva ER, Falavigna A. Use of methylphenidate among medical students: a systematic review. Rev Assoc Med Bras. 2013;59(3):285-9. PMID: 23680277; doi: 10.1016/j.ramb.2012.10.007.

32. Dal Pizzol TS, Branco MMN, Carvalho RMA, et al. Uso não-médico de medicamentos psicoativos entre escolares do ensino fundamental e médio no Sul do Brasil [Non-medical use of psychoactive medicines among elementary and high school students in Southern Brazil]. Cad Saúde Pública. 2006;22(1):109-15. PMID: 16470288; doi: 10.1590/ S0102-311X2006000100012.

Authors' contributions: KLSB and FFCC conceived and designed the experiments; GF, GF, GC and TP performed the experiments; KLSB and LR analyzed and interpreted the data; EG and DNM contributed reagents, materials, analysis tools or data; KLSB, LR, EG and DNM wrote the paper. All authors read and approved the final manuscript

Sources of funding: This research did not receive any specific grant from any funding agencies in the public, commercial or notfor-profit sectors

Conflict of interest: The authors declare that there were no conflicts of interest

Date of first submission: May 28, 2019

Last received: October 4, 2019

Accepted: October 21, 2019

\section{Address for correspondence:}

Lilian Rigo

Faculdade Meridional (IMED)

Rua Senador Pinheiro, 304

Passo Fundo (RS) - Brasil

CEP 99070-220

Cel. (+55 54) 3045-6100

E-mail: lilian.rigo@imed.edu.br 